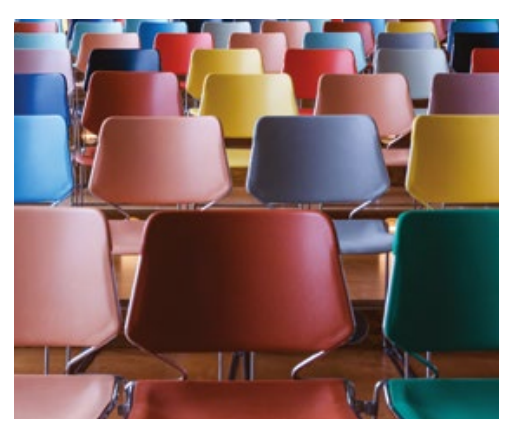

CPD

Richard Hays, Tarun Sen Gupta

\section{Background}

Australia continues to develop as a multicultural nation, with a population that is ageing and developing complex health needs. The world around us is changing, and the pace of change is increasing. These contextual changes pose challenges for general practice training.

\section{Objectives}

This paper explores the potential impact of these changes on the general practice workforce.

\section{Discussion}

General practitioners (GPs) will continue to have a central role in coordinating continuous, comprehensive care but are more likely to act as managers of multi-source, continuous monitoring data that facilitate personalised medical care. GPs will need to adapt rapidly to change, seizing opportunities offered by disruptive technology in a globalised world affected by climate change. The nature and impact of change is difficult to predict, and more research is needed to explore how change will affect healthcare and healthcare professionals. Ideally, training for general practice should include preparation for managing continuous change.

\title{
Developing a general practice workforce for the future
}

IN 2018, Australia's population of about 24.5 million people ${ }^{1}$ lives mostly in coastal urban centres concentrated in the south and east. There are many under-served populations, including those residing in mushrooming urban conurbations, migrants and marginalised groups such as those in prison, drug addicts and sex workers. Health status is also substantially different for Aboriginal and Torres Strait Islander peoples and all peoples living in more remote communities. ${ }^{2}$ Poor access to healthcare is a common factor for these populations.

Part of the access issue is the maldistribution of medical services, including general practitioners (GPs). The most recent estimate of the current general practice workforce is about $24,000 .^{3}$ Like the rest of the community, GPs prefer to live in larger coastal communities and are under-represented in small rural and remote communities. ${ }^{4}$ As part of a National Strategic Framework for Rural and Remote Health, ${ }^{5}$ a range of medical education initiatives has increased the supply of basic medical graduates and expanded specialty training programs for general practice and rural medicine. These initiatives have been generally successful, although less so in smaller rural and remote communities. ${ }^{4}$

Particularly where access to healthcare is good, recent advances in medicine have enabled people to live longer, often with multiple chronic diseases slowly progressing in parallel. As a result, GPs have had to assume a major role in balancing contributions from several narrower specialties, explaining options, managing potentially conflicting management plans and helping patients make choices: the emphasis is on personalising patient management amid complexity. At the same time, substantial progress has been made in implementing evidence-based strategies for preventing or delaying disease through population-based approaches. ${ }^{6}$ General practice is the ideal place to combine these complementary roles.

While the nation struggles to address these differences in demography, access and workforce supply, we live in a dynamic situation where change continues, probably at an increasing rate. ${ }^{7}$ Climate change, technology development and globalisation may happen faster than our ability to adapt, posing challenges for many facets of society. This paper discusses likely trends that will shape future healthcare provision and how the general practice workforce may have to adapt to serve the more complex needs of an increasing, ageing and more chronically unwell population in an era when the ready availability of abundant, unfiltered knowledge means that experienced, professional judgement may be even more important.

\section{What kind of general practice workforce do we need?}

There is likely to be little change in the professional roles of doctors. Medical codes of conduct expand basic definitions of professionalism by describing qualities such as compassion, caring, responsibility and expertise. ${ }^{8}$ The 2010 Lancet Commission described an evolution in medical education from informative learning (acquiring knowledge and skills 
in order to produce experts) to formative (socialising students around values to produce professionals) to transformative learning (developing leadership attributes to produce enlightened change agents). ${ }^{9}$

The Australian Medical Council's

Graduate Outcome Statements are organised into four domains (Box 1), which highlight wider roles beyond knowledge and skills. ${ }^{10}$ Both The Royal Australian College of General Practitioners and the Australian College of Rural and Remote Medicine provide curriculum descriptions relevant to general practice training. ${ }^{11,12}$ These will continue to evolve, emphasising the central role in ongoing, comprehensive care for serving a population with access to the most recent health information, albeit amid large amounts of misinformation and opinion that is not evidence-based. The need for managing undifferentiated illnesses will continue, as will the need for management of chronic disease and mental health disorders. GPs may become facilitators of decision making by patients, based on data from several sources, rather than necessarily being the data gatherers and decision makers. ${ }^{13}$ Distinctions may blur between what we now call primary care and ambulatory care components of secondary care, with patients, rather than their problems, at the centre.

\section{Future needs of the population}

The prevalence of obesity continues to rise, increasing susceptibility to chronic diseases. Significant advances will continue in cancer treatment and immunogenetics, increasing

\section{Box 1. The four domains of the Australian Medical Council's graduate outcome statements ${ }^{10}$}

1. Science and Scholarship: the medical graduate as scientist and scholar

2. Clinical Practice: the medical graduate as practitioner

3. Health and Society: the medical graduate as a health advocate

4. Professionalism and Leadership: the medical graduate as a professional and leader the complexity of multiple parallel disease management. Not all trends are predictable. It was once thought that more coronary artery bypass grafts (CABGs) would be necessary; however, medical management has reduced the need for CABGs substantially. Bariatric surgery for obesity, now relatively inaccessible, may become either more available to manage many chronic diseases or be made redundant by improved medical management. Many congenital diseases and acute malignant conditions that were once rapidly fatal are now chronic diseases. Antibiotic resistance is increasing, potentially increasing the risks of infectious diseases. ${ }^{14}$ Climate change may affect certain populations and communities through environmental changes and possible mass migration. ${ }^{15}$

\section{Impact of technology}

Access to nationwide, high-speed data transmission is likely to improve, enabling current medical information to be as available to patients as to professionals. Many chronic diseases may be monitored by apps that collect and transmit data to patient record systems. ${ }^{16}$ It is likely to become more common for patients to consult GPs for advice on the results of their searches, seeking help to act on the choices that patients learn are available.

Some GP tasks are already within the scope of simple artificial intelligence (AI) systems. Repeat prescriptions may be authorised through practice information systems via mobile devices when app-fed data monitoring confirms patient stability. Deviations from stability may be detected earlier and result in recalling of patients directly for intervention. Management of new conditions may be assisted by feeding patient-generated information through software that recognises patterns and initiates investigations and care pathways. Investigation results may be conveyed to patients automatically, with options from 'all is fine, no action necessary' to 'urgent appointment'. The AI systems may, over time, develop a detailed understanding of patients' individual circumstances, enabling optimisation of evidence-based care. GPs may spend most of their effort managing patients either remotely or in longer consultations, sorting out complexity. There are implications for fee schedules, practice design and integration with other health services. Some of this technology is available now and may become more accessible and affordable quite soon.

\section{Future needs of general practitioners}

GPs are not immune to broader societal challenges. Hours worked and numbers of patients seen have slowly decreased. The interpretation of 'full time' has changed, and many GPs, both men and women, share parenting or work in more than one professional role. ${ }^{17}$ This trend is likely to continue as GPs seek a better work-life balance.

The trend to acquiring part-time sub-specialisations will continue. In urban practice, most interest is in skin cancer, sports medicine, cosmetic medicine and complementary medicine. In rural practice, procedural disciplines (eg obstetrics, anaesthetics, emergency medicine) may increase with the expansion of the national rural generalist pathway. ${ }^{18}$ Other disciplines, such as palliative care, mental health, paediatrics and adult internal medicine, may be more necessary and become more popular, potentially increasing the diversity of practitioners within general practice. True generalism can be hard work and may become less common as larger groups of GPs are employed to work part time in large clinics to provide a wide range of services.

Work practice changes may be influenced by changes in preferences and interests of the workforce. The impact of generational change on medical education has been described, ${ }^{19}$ although changes are generally more gradual than a simplistic twenty-year definition of a generation. Students currently entering medical schools seem to share characteristics such as assertiveness, high expectations and altruism. ${ }^{19}$ They are also technologyreliant and prefer more flexible, personalised learning. The culture of medical education is changing. 
Of particular concern is the reported increased stress and lower resilience of this group. ${ }^{20}$ Some young doctors respond poorly to pressure and criticism, despite having chosen a demanding career where pressure to be correct is high, peer review and feedback is the norm and public scrutiny is increasing. Registrars training for rural practice may need to be more resilient to succeed in rural communities. ${ }^{21}$ Is the situation worse than in the past or simply more overt because of social media exposure? Can resilience be improved through training? ${ }^{22}$ More research is needed, as it is important that medical graduates expect, manage and perhaps even thrive on change in order to meet the needs of the communities of the future.

\section{Addressing the maldistribution}

One current approach to developing a fit-for-purpose medical workforce - 'the right people with the right skills in the right places' - is to expand training in under-served communities. This strategy has been the focus of the rural medical education movement at undergraduate and postgraduate levels for the past 20 years and is supported by financial incentives from the government. , $23,24^{2}$ This has not been as effective in more remote communities, ${ }^{4}$ where the medical workforce remains heavily dependent on international medical graduates, who play a vital part in maintaining services in under-served communities. A fairer system is necessary to ensure more equitable distribution of both domestic and international graduates.

Sustainability requires more than short-term incentives, as both local and national factors are involved. ${ }^{25,26} \mathrm{New}$ medical workforce and practice models are emerging, such as the amalgamation of practices in several adjacent under-served communities. These share staff (medical nursing and administrative), record systems and practice management across locations; Queensland's Central West Single Practice model is one example. ${ }^{27}$ This approach reduces management costs, allows for a mix of staff and broader service mix that best suits needs, and provides internal cover for after-hours access and leave. Staff may include a mix of full-time local staff and part-time staff, some of the latter on a 'drive-in, driveout' or 'fly-in, fly-out' basis from more popular communities. ${ }^{28}$ Practices in larger communities could be 'buddy' practices, providing the visiting staff and external support. Many variations on this theme are developing, built on local opportunities and constraints.

\section{Conclusion}

Predicting the future is difficult, but it is likely that more rapid changes will occur. Emerging technology may disrupt and profoundly change how GPs work. The broad trends of increasing case mix complexity and changing workforce participation are likely to continue, perhaps influenced by climate change and globalisation, as well as societal trends to patient autonomy, availability of information and more personalised care. New specialties and special interests may emerge, while others may decrease in prominence, but general practice may become even more central in managing complex care across primary, secondary and tertiary healthcare. There are implications for general practice training, which must provide personalised learning that prepares graduates for current practice with the capacity to adapt rapidly to inevitable change, ideally leading the application of the changes to enhance healthcare for all communities.

As Yogi Berra observed, 'The future ain't what it used to be'. ${ }^{29}$ As GPs, we need to get used to this idea and prepare for it. And who better to manage future healthcare needs than the GP, the master of uncertainty?

\section{Authors}

Richard Hays MBBS, MD, PhD, FRACGP, FACRRM, FRCGP, Professor of Remote and Rural Health, College of Medicine and Dentistry, James Cook University, Townsville, QId; University of Tasmania, Hobart, Tas. richard.hays@jcu.edu.au

Tarun Sen Gupta MBBS, PhD, FRACGP, FACRRM, Professor of Health Professional Education, College of Medicine and Dentistry, James Cook University, Townsville, Qld

Competing interests: None.

Provenance and peer review: Commissioned, externally peer reviewed.

\section{References}

1. Australian Bureau of Statistics. Australian demographic statistics, June 2017. Cat. no. 3101.0. Canberra: ABS, 2017. Available at www.abs.gov. au/AUSSTATS/abs@.nsf/mf/3101.0 [Accessed 4 April 2018].

2. Australian Institute of Health and Welfare. Australia's health 2016. Australia's health series no. 15. Cat. no. AUS 199. Canberra: AlHW, 2016. Available at www.aihw.gov.au/reports/australiashealth/australias-health-2016/contents/summary [Accessed 4 April 2018].

3. Australian Health Practitioner Regulation Agency. Managing risk to the public: Regulation at work in Australia. Melbourne: AHPRA, 2017. Available at www.ahpra.gov.au/annualreport/2016 [Accessed 4 April 2018].

4. Walters LK, McGrail MR, Carson DB, et al. Where to next for rural general practice policy and research in Australia? Med J Aust 2017;207(2):56-58. doi: 10.5694/mja17.000216.

5. Department of Health. National strategic framework for rural and remote health. Canberra: DoH, 2016. Available at www.health. gov.au/internet/main/publishing.nsf/content/ rural+health-1 [Accessed 4 April 2018].

6. Hays RB. Including health promotion and illness prevention in medical education: A progress report. Med Educ 2018;52(1):68-77. doi: 10.1111/ medu.13389.

7. Friedman TL. Thank you for being late: An optimist's guide to thriving in the age of accelerations. New York: Farrar, Straus and Giroux, 2016.

8. Australian Health Professions Regulatory Authority. Good medical practice: A code of conduct for doctors in Australia. Melbourne: AHPRA [date unknown]. Available at www. medicalboard.gov.au/Codes-Guidelines-Policies/ Code-of-conduct.aspx [Accessed 4 April 2018].

9. Frenk J, Chen L, Bhutta ZA, et al. Health professionals for a new century: Transforming education to strengthen health systems in an interdependent world. Lancet 2010;376(9756):1923-58. doi: http://dx.doi. org/10.1016/S0140-6736(10)61854-5.

10. Australian Medical Council. Standards for assessment and accreditation of primary medical programs by the Australian Medical Council 2012. Kingston, ACT: AMC, 2012. Available at www. amc.org.au/joomla-files/images/Accreditation/ FINAL-Standards-and-Graduate-OutcomeStatements-20-December-2012.pdf [Accessed 31 May 2018].

11. Royal Australian College of General Practitioners. Curriculum for Australian general practice. Melbourne: RACGP, 2016. Available at www. racgp.org.au/education/curriculum [Accessed 4 April 2018].

12. Australian College of Rural and Remote Medicine. Primary curriculum. 4th edn. Brisbane: ACRRM, 2016. Available at www.acrrm.org.au/docs/defaultsource/documents/training-towards-fellowship/ primary-curriculum-august-2016.pdf?sfvrsn=0 [Accessed 4 April 2018].

13. Susskind R, Susskind D. The future of the professions. Oxford, UK: Oxford University Press, 2015.

14. World Health Organization. Antimicrobial resistance. Fact sheet. Geneva: WHO, 2018. Available at www.who.int/en/news-room/factsheets/detail/antimicrobial-resistance [Accessed 21 May 2018].

15. Carrington D. Climate change already bringing disease, air pollution and heatwaves. The Guardian. 31 October 2017. 
16. Hays R. Healthcare apps. Aust Fam Physician 2016;45(11):849-50.

17. Joyce $C$, Scott $A$, Jeon $S$, et al. The 'Medicine in Australia: Balancing Employment and Life (MABEL)' longitudinal survey - Protocol and baseline data for a prospective cohort study of Australian doctors' workforce participation. BMC HIth Serv Res 2010;10:50. doi: 10.1186/1472-696310-50.

18. Department of Health (DoH). Stronger rural health - Training - Streamlining general practice training to produce Australian trained general practitioners where they are needed. Canberra: DoH, 2018. Available at www.health.gov.au/internet/budget/ publishing.nsf/Content/budget2018-factsheet24. htm [Accessed 21 May 2018].

19. Twenge JM. Generational changes and their impact in the classroom: Teaching generation Me. Med Educ 2009;43(5):398-405. Available: doi: 10.1111/j.1365-2923.2009.03310.x

20. Cooke G, Doust J, Steele MC. A survey of resilience, burnout, and tolerance of uncertainty in Australian general practice registrars. BMC Med Educ 2013;13:2. doi: 10.1186/1472-6920-13-2.
21. Eley DS, Leung JK, Campbell N, Cloninger CR. Tolerance of ambiguity, perfectionism and resilience are associated with personality profiles of medical students oriented to rural practice. Med Teach 2017;39(5):512-19. doi: 10.1080/0142159x.2017.1297530.

22. Cheshire A, Hughes J, Lewith G, et al. GPs' perceptions of resilience training: A qualitative study. Br J Gen Pract 2017;67(663):e709-15. doi:10.3399/bjgp17X692561.

23. Department of Health. Regional training hubs. Canberra: DoH, 2017. Available at www.health.gov. au/internet/main/publishing.nsf/content/regionaltraining-hubs [Accessed 29 January 2018].

24. Sen Gupta T, Woolley T, Murray R, Hays R, McCloskey T. Positive impacts on rural and regional workforce from the first seven cohorts of James Cook University medical graduates. Rural Remote Health 2014;14(1):2657.

25. Bourke L, Humphreys JS, Wakerman J, Taylor J. Understanding rural and remote health: A framework for analysis in Australia. Health Place 2012;18(3):496-503. doi:10.1016/j. healthplace.2012.02.009.
26. Chater B. Looking after health care in the bush. Aust Health Rev 2008;32(2):313-18.

27. Rimmer D, Knight S, Douyere J, Keating T. Central West single practice service model. Proceedings of Rural Medicine Australia Conference 2015. Queensland: Queensland Government, 2015. Available at http://ruralgeneralist.qld.gov.au/ wp-content/uploads/2017/07/cwhhs-sinpracserv. pdf [Accessed: 29 January 2018].

28. Margolis SA. Is Fly-in/Fly out (FIFO) a viable interim solution to address remote medical workforce shortages? Rural Remote Health 2012;12:2261.

29. Berra Y. Quote. Available at www.brainyquote. com/quotes/yogi berra 102747 [Accessed 7 April 2018].

correspondence ajgp@racgp.org.au 